\title{
Solving Medicare's Fiscal Crisis: An Analysis of Three Policy Options
}

\author{
By Ashley Flint
}

Health care spending in the United States has increased rapidly over the past several decades. Medicare, the largest public health insurance program in the US, is a key component of these growing costs. While Medicare financing is expected to be stable over the next decade, the long-term solvency will be difficult to sustain absent congressional action. This paper analyzes three policy options for Congress to consider in addressing the problem of rapid cost growth in the Medicare program.

\section{Introduction}

\section{Problem}

National health expenditures in the United States have increased more than tenfold over the past three decades, increasing from $\$ 255.8$ billion or 9.2 percent of US Gross Domestic Product (GDP) in 1980 (DHHS 2012a) to nearly $\$ 2.6$ trillion in 2010, or 17.9 percent of GDP according to the Centers for Medicare and Medicaid Services, Office of the Actuary, National Health Statistics Group; and US Department of Commerce, Bureau of Economic Analysis and Bureau of the Census (Martin et al. 2012). Over the next several years, national health expenditures are projected to continue growing rapidly, reaching more than $\$ 4.6$ trillion by 2020 , or about 19.8 percent of GDP according to recent estimates (DHHS 2011a). US health spending as a percentage of GDP is the highest of all other developed nations around the world (OECD 2011). Despite this spending, widely-accepted health outcome measures such as life expectancy and infant mortality rates suggest that Americans are not any healthier for the high cost (CEA 2009). Rapid health care cost growth coupled with the recent economic downtown have created significant financial challenges for the federal government (KaiserEDU.org 2012), with government programs accounting for over a third of all US health spending (DHHS 2012b). One way that Americans receive health insurance coverage, especially those over the age of 65, is through Medicare, the second-largest public insurance program in the US. Medicare provided coverage to more than 47 million elderly and disabled Americans in 2010, representing about 15 percent of the entire US population. Given its large size, the Medicare program's growing health care costs have been and continue to be a key driver of federal expenditures and projected budget deficits (Medicare Board of Trustees 2011; Davis 2011). Total Medicare expenditures in 2010 amounted to approximately $\$ 524.6$ billion, accounting for 20 percent of all health expenditures in the US according to the Centers for Medicare and Medicaid Services, Office of the Actuary, National Health Statistics Group (Martin et al. 2012) and just over 15 percent of total federal spending that year, according to the Congressional Budget Office (Fuchs and Potetz 2011). This figure has more than doubled in the past decade, increasing from just $\$ 224$ billion in 2000 
according to the Centers for Medicare and Medicaid Services, Office of the Actuary, National Health Statistics Group (Martin et al. 2012). Furthermore, Medicare expenditures are projected to increase to $\$ 864$ billion by 2021 , or 16 percent of total federal spending in that year, according to the Kaiser Family Foundation (New York Times Editorial Board 2011).

The Affordable Care Act, signed into law by President Barack Obama in March 2010, includes several provisions that will impact how Medicare pays for health services, the types of benefits covered under the program, and how care is delivered (Davis et al. 2011). Though these provisions are projected to decrease expenditures in the Medicare program relative to previous baseline projections, spending commitments in the program are projected to outpace future economic growth and will continue to consume an ever-increasing portion of federal budgetary resources over time (Davis 2011). If Congress does not take action, then the financial viability of the Medicare program will be difficult to sustain in the long-term (Davis et al. 2011). Furthermore, the Medicare Board of Trustees (2011) has stated that there is a significant need for further steps to address future financial challenges in the program.

\section{Context}

Medicare Part A, the Hospital Insurance component of the program, is financed by dedicated payroll taxes that sustain the Hospital Insurance trust fund (Davis et al. 2011). The projected financial solvency of this fund has been significantly improved by provisions in the Affordable Care Act, including increased tax revenue through an additional 0.9 percent payroll tax on high-income workers beginning in 2013 (Medicare Board of Trustees 2011). Despite these improvements, it is still expected that the Hospital Insurance trust fund will become insolvent by 2024, a full five years earlier than last reported by the Medicare Board of Trustees in 2010
(2011). Furthermore, over the next 75 years, revenues from payroll taxes, which sustain the Hospital Insurance trust fund, are expected to fall short of expenditures in this component of the program by approximately $\$ 3.3$ trillion (Davis 2011). Medicare Part B, which covers physician and other outpatient services, is financed under an account within the Supplementary Medical Insurance trust fund (Davis 2011). This fund relies on both premiums paid by beneficiaries and general revenues from the federal government for financing (Davis et al. 2011). Beneficiary premiums cover about 25 percent of costs under Medicare Part B while general revenues comprise the remaining 75 percent (Van de Water 2011). According to the most recent estimates from Medicare Board of Trustees (2011), the Supplementary Medical Insurance trust fund is adequately financed over the next decade, meaning that expected program revenues will cover projected costs in the program during this time frame. However, because beneficiary premiums do not keep pace with overall expenditure growth in the program, the Supplementary Medical Insurance trust fund is projected to draw on a greater portion of federal government general revenues over time, increasing from 19.2 percent in 2010 to 26.3 percent by 2080 . This figure has already increased substantially over the last decade, up from just 5.4 percent as recently as 2000, according to the Medicare Board of Trustees (Davis 2011). Additionally, actual future expenditures in Medicare Part B are likely to be even higher than currently projected if scheduled cuts to physician reimbursement rates under the Sustainable Growth Rate formula continue to be postponed by Congress (Medicare Board of Trustees 2011). Created by the Balanced Budget Act of 1997, the purpose of the Sustainable Growth Rate formula was to control the rate of growth in Medicare spending for physician services by establishing annual spending targets based on GDP growth (Hahn and Mulvey 2011). However, actual 
expenditures in Part B began to exceed allowed targets beginning in 2002, a difference that has continued to grow each year. While Congress allowed a 4.8 percent decrease in Medicare physician reimbursement rates in 2002, legislators have regularly postponed subsequent scheduled cuts over the past decade (Hahn and Mulvey 2011). Despite these delayed cuts, when government entities such as the Congressional Budget Office or the Medicare Board of Trustees project future Medicare expenditures, their estimates are based on current law and therefore the expectation that these scheduled reductions in physician reimbursement rates will be implemented (Medicare Board of Trustees 2011). While financing for the various components of Medicare program is currently expected to be stable for the next decade, in part due to changes under the Affordable Care Act, several key factors are currently driving the steep rate of cost growth in the program and will continue to do so in the future. First, there has been a significant increase in the overall cost of providing health care services in the US as new treatments and technologies are continually developed (Davis et al. 2011; New York Times Editorial Board 2011). Similarly, there has been an increase in the intensity and volume of medical services provided per Medicare beneficiary compared to historical utilization rates (Davis et al. 2011). This trend is also expected to continue in future years (Medicare Board of Trustees 2011).

One of the most significant drivers of Medicare spending in coming years will be the aging American population as the baby boomer generation reaches age 65 and becomes eligible for benefits under the program (Medicare Board of Trustees 2011). It has been estimated that an average of 10,000 baby boomers will turn 65 every day for the next 20 years (Montgomery 2011), and Medicare enrollment is expected to increase to nearly 80 million individuals by 2030 (Pear 2011). Another important demographic trend impacting the Medicare population is continued improvements in life expectancy over time (Medicare Board of Trustees 2011). Seniors, on average, are living much longer once they reach retirement age and drawing on Medicare benefits for more years than previous generations of beneficiaries. In 1965, when the Medicare program was enacted, the average American life expectancy at birth was approximately 70 years. With beneficiaries becoming eligible for the program at age 65 , this meant that Medicare provided health care in the average beneficiary's last five years of life. However, by 2010, the average American life expectancy at birth rose to over 78 years. Thus, the Medicare program is now covering, on average, the last 13 years of a beneficiary's life, a 158 percent increase since the program was enacted (Roy 2011).

Finally, elderly and disabled Medicare beneficiaries generally tend to live with multiple chronic health conditions, which greatly increase their utilization of health care services. More than half of all current beneficiaries live with five or more chronic conditions, such as diabetes, hypertension, and heart problems, according to the US Department of Health and Human Services (DHHS 2011b). If this trend continues with future generations of program beneficiaries, it could create a complicated and costly situation, especially under the often fragmented and uncoordinated health care delivery system in the US (Newman 2011).

\section{Overview of the Analysis}

The rising cost of providing health care and the changing demographics in the US population present key challenges to the long-term financial sustainability of the Medicare program. Several policy options to address this problem have been proposed and discussed by federal policymakers within Congress and the administration, especially in the context of longterm federal deficit reduction. However, consensus between the two political parties on the best path forward for Medicare has been elusive. Nevertheless, given the 
strain created by the Medicare program on the budget, it is in the best financial interest of the federal government to take further action to control rapid spending growth in the program. Medicare is administered and financed solely by the federal government and thus it is a field in which Congress is the only entity that is empowered to take legislative action on this issue.

The following policy analysis evaluates three proposed reforms to the Medicare program that would require congressional action: (1) incorporating comparative effectiveness research into the Medicare coverage and reimbursement process by linking reimbursement rates to the effectiveness of a particular treatment, (2) expanding the Accountable Care Organization demonstration program that is currently being implemented under the Affordable Care Act in order to better coordinate care for Medicare beneficiaries and reduce the cost of providing care, and (3) transforming the traditional Medicare program into a premium support model in which beneficiaries would receive a subsidy to purchase private health insurance coverage, based on the proposal from House Budget Committee Chairman Paul Ryan (R-WI) in his Fiscal Year (FY) 2012 Budget Resolution. Each policy option will be described in detail and evaluated based on four criteria. These criteria include the efficacy, overall cost, political feasibility, and potential limitations of each policy option.

The four criteria utilized in this analysis were selected to provide a comprehensive illustration of the expected impact of each policy option. Given the concern for the federal budget and projected deficits, efficacy at reducing spending in the Medicare program and the overall cost to the federal government of achieving this goal are imperative to consider in analyzing each proposal. The political feasibility of each policy option is also essential because the most efficacious or least costly proposal is futile unless it can navigate the legislative process and be en- acted into law. Finally, it is important to consider potential limitations to ensure that there are no unintended consequences of pursuing a particular policy option.

\section{Description of Criteria}

The first criterion will evaluate the efficacy of each policy option in addressing the problem. The first objective is to reduce Medicare expenditure growth, and this outcome will be measured based on the dollar amount of savings expected to result from a particular policy change. The dollar amount of estimated savings will be categorized as either significant or insignificant. Significant savings will reduce expenditure growth in the Medicare program by a minimum of 1 percent annually, or approximately $\$ 5$ billion based on current annual expenditures. Savings that do not approach this threshold would have such a minimal impact on overall spending in the Medicare program that they will be considered insignificant for the purposes of this analysis. The reasoning behind this threshold for significant savings is based a framework for evaluating cost control proposals, developed by Emanuel (2012).

The second objective is to reduce Medicare costs without compromising the quality of care provided to beneficiaries. Assessing the impact of each policy option on the quality of care delivered is not as easily quantifiable as estimated dollar savings. Instead, outcomes on this measure will be classified as having no impact on, improving, or worsening the quality of care and health outcomes, based on existing evidence or expected impact. The most successful outcome on this measure will improve the quality of care and health, and the least successful outcome would worsen the quality of care and health. An intermediate outcome on this measure would have no impact on the quality of care or health.

The second criterion will evaluate the monetary cost to the federal government of implementing each policy option. The overall cost of each policy change will be based on estimates reported in the lit- 
erature, and the most successful outcome on this criterion will have the lowest net cost, or only minimal costs, to implement. The third criterion, political feasibility, will assess the viability of each policy proposal based on the political environment in Congress, interest group involvement, and public receptivity to the proposed change. The political environment in Congress will be evaluated by considering information such as current policy priorities, partisan composition, and demonstration of support for similar legislation in the past. Next, the most powerful interest groups with a stake in the proposed change to the Medicare program will be identified, and their involvement with similar legislation in the past or current positions on the issues will be examined, where information is available. Interest group involvement will be classified as supportive or in opposition, and by degree-whether low, moderate, or strong. Finally, public receptivity will be assessed by examining public opinion regarding the policy proposals, or similar proposals in the past, including any polling that might be available. Public receptivity will also be categorized as supportive or in opposition, and by degree-whether low, moderate, or strong. Finally, the fourth criterion will assess potential limitations of each policy by looking to recent research and literature that reports possible unintended consequences of each proposal. These potential limitations will also be evaluated in terms of how they might impact the expected outcomes as assessed on the first three criteria. In assessing the potential limitations of each policy option, special attention will be paid to whether the proposal actually reduces the overall cost of providing health care under the Medicare program, as opposed to shifting the cost of care onto other groups, such as beneficiaries or health care providers. Potential limitations for each option will be classified as minimal, moderate, or significant.

\section{Option One: Incorporate Comparative Effectiveness Research into Medicare Coverage and Reimbursement Decisions}

The following section provides a description ofthefirstpolicyoptionandthen evaluates the proposal based on each of the four criteria described in the introduction.

\section{Description of Option One}

One policy option is to transform the way that health care providers are paid for the services they deliver to Medicare beneficiaries, based on a proposal put forward by physicians Dr. Steven Pearson and Dr. Peter Bach. Dr. Pearson is the founder and president of the Institute for Clinical and Economic Review, and Dr. Bach previously served as a senior adviser to the administrator of the Centers for Medicare and Medicaid Services.

Under current law, Medicare coverage and reimbursement decisions are made in two distinct processes. First, the Centers for Medicare and Medicaid Services, the administrative agency for the Medicare program, determine whether or not to cover a new service or treatment based on whether it is deemed "reasonable and necessary," a definition included in the original statutory language when the Medicare program was enacted in 1965 (Seiguer 2005). Reimbursement rates are then calculated through separate payment formulations based on the type of service and the location where it is rendered, a process which can lead to wide variation in reimbursement rates for the same service (Pearson and Bach 2010). These rates reflect the underlying cost of the service, and providers are compensated each time a service is rendered. This emphasis on volume thus creates a strong financial incentive to use, and potentially overuse, expensive treatments according to Newhouse (as cited in Pearson and Bach 2010) relative to less costly treatment options that may have comparable effectiveness in achieving the desired clinical outcome.

Rather than continuing to use the 
current Medicare fee-for-service payment model that tends to incentivize overutilization of medical services, Drs. Pearson and Bach (2010) propose linking the determination of reimbursement rates to comparative effectiveness research. To make this change in the current Medicare administrative system, an audit of all treatments and services currently covered by the program would need to be performed, and then reimbursement rates for any new treatment options moving forward would be set using this new process. Under this proposed new system, the current evidence threshold of "reasonable and necessary" would still be utilized. However, once the initial coverage decision is made, a subsequent assessment would evaluate the treatment's comparative effectiveness in relation to other similar treatment options. Based on existing evidence, services would be assigned to one of three categories: "superior comparative clinical effectiveness," "comparable comparative clinical effectiveness," or "insufficient evidence to determine comparative clinical effectiveness" (Pearson and Bach 2010).

According to Drs. Pearson and Bach (2010), a treatment would be designated as having superior clinical effectiveness if there is enough evidence to establish that the treatment is either more effective or has less severe side effects than other related treatments. For this type of service, reimbursement rates would continue to be determined based on the current Medicare formula, which compensates providers based on the underlying cost of providing the treatment. In the next category, a service is designated as having comparable clinical effectiveness if there is adequate evidence to demonstrate that the effectiveness of the treatment is similar to other related treatment options. In this instance, reimbursement rates would be set at a level equal to that comparable option, a process known as reference pricing.

Finally, Drs. Pearson and Bach (2010) propose that when the existing evidence is not sufficient to determine wheth- er a treatment is superior, comparable, or inferior relative to other treatment options, the reimbursement rate would initially be set according to the current Medicare formula, but only for a probationary period of three years. At the end of this time period, new evidence would be evaluated, and if the latest evidence demonstrates the superior effectiveness of a service, the existing reimbursement formula would continue to be utilized. However, if the evidence shows no comparative advantage, or there is still insufficient evidence, reimbursement rates would be reduced to the reference price for the most comparable treatment option. Furthermore, if evidence suggests that the treatment is inferior relative to other service options, the Centers for Medicare and Medicaid Services would be required to reevaluate whether or not the treatment still meets the "reasonable and necessary" standard for coverage. Additionally, treatments that are designated as having superior or comparable effectiveness will also be subject to review every three years in order to ensure the current classification is appropriate based on any new clinical evidence.

This policy change would rely heavily on the availability of sound clinical comparative effectiveness research in order to make appropriate coverage and reimbursement decisions for the Medicare program. The Affordable Care Act established the Patient-Centered Outcomes Research Institute (the Institute), a nongovernmental organization to coordinate and evaluate national comparative effectiveness research (Copeland 2010). Beginning in FY 2012, the Institute will contract with and provide funding for eligible entities, including federal agencies, academic institutions, and private research organizations, to conduct clinical comparative effectiveness research. All studies will conform to the peer-review process and adhere to methodological standards that will be established by the Institute's methodology committee, composed of 15 experts in the field of comparative effectiveness 
research. The Institute will then systematically review both existing evidence and evidence from new studies, and disseminate its findings to patients and providers (Copeland 2010). Based on current law, the Centers for Medicare and Medicaid Services, which is responsible for making Medicare coverage and reimbursement decisions, is not permitted to consider comparative effectiveness research in making such decisions except in very rare circumstances (Pearson and Bach 2010). Therefore, in order for this policy option to be successfully implemented, Congress would also need to provide broader authority to the Centers for Medicare and Medicaid Services to make these decisions based on the findings of comparative effectiveness research, as facilitated by the Institute and any other relevant entities.

Expected Outcomes of Option One

\section{Efficacy}

Many budget experts, including the Congressional Budget Office, have identified long-term Medicare expenditures and their impact on federal deficits as one of the main fiscal challenges currently facing the US (Davis 2011). Drs. Pearson and Bach (2010), the authors of this proposed policy option, predict that restructuring the system would produce significant savings in the federal government's Medicare expenditures. The authors provide an example of the potential savings for one type of treatment covered by Medicare that is illustrative of the overall savings that could result from this policy change.

Under existing Medicare payment policies, there are two main services that are reimbursed for the treatment of prostate cancer. Reimbursement for a single course of the newer treatment, intensitymodulated radiation therapy, is set at $\$ 42,000$, compared to $\$ 10,000$ for the conventional treatment, three-dimensional therapy (Pearson and Bach 2010). Intensity-modulated radiation therapy has been estimated to add approximately $\$ 1.5$ billion annually to Medicare expenditures, solely for the treatment of prostate cancer, according to Profits and Konski et al. (as cited in Pearson and Bach 2010). This additional cost has been covered without any evidence to demonstrate that this treatment is more effective than other, lesscostly treatment options. Given the multitude of services and treatments that are covered and paid for by Medicare, more than 7,000 distinct services according to recent estimates (New York Times Editorial Board 2011), the savings that could be realized through this policy proposal have the potential to be significant. Even if only 5 to 10 percent of the total number of services covered by Medicare achieves a quarter of the savings realized in this example, it would amount to between approximately $\$ 131$ billion and $\$ 262$ billion in annual savings for the program.

The nature of this policy change, which promotes the use of standardized clinical comparative effectiveness research to determine which treatments lead to the most effective health outcomes, also suggests the strong likelihood of an improvement in the quality of patient care and improved health outcomes for Medicare beneficiaries. This reform emphasizes higher reimbursement rates for treatments based on clinical effectiveness, as opposed to the underlying cost of the treatment. Thus, an incentive would be created for physicians to utilize those interventions that have actually demonstrated superior health outcomes for patients. Similarly, restructuring the Medicare payment system in this manner has the potential to shift the focus of innovation in the medical field by incentivizing effectiveness over profit (Pearson and Bach 2010), which could also possibly lead to improved health outcomes.

\section{Implementation Cost}

The cost of implementing this new payment model for the Medicare program would likely only impose minimal costs on the federal government. The adminis- 
trative structure that makes coverage and reimbursement decisions, the Centers for Medicare and Medicaid Services, already exists and thus, the establishment a new agency would not be necessary to implement the policy change (Pearson and Bach 2010). An audit of current coverage and reimbursement practices with the new payment model might require the reallocation of already appropriated funds or, if needed, an additional request for funds. In 2010, administrative expenses in the Medicare program amounted to approximately $\$ 7$ billion (Medicare Board of Trustees 2011). Therefore, even if administrative costs doubled to $\$ 14$ billion in order to accommodate these coverage and reimbursement reforms, the additional costs would be minimal compared to the potential savings that could be realized under the policy change.

\section{Political Feasibility}

A significant change to the Medicare coverage and reimbursement system is likely to be controversial. However, given the challenging long-term financial outlook for the Medicare program and the almost singular focus on federal deficit reduction in the $112^{\text {th }}$ Congress, the viability of such a drastic policy change has improved significantly in the past 15 months. During that time frame, both political parties have demonstrated a willingness to come to the table and consider major changes to the Medicare program that would not have been possible previously.

Beyond Congress, there are likely to be several key interest groups involved if this policy change were to be pursued. First, significant reforms to the Medicare coverageand reimbursement system would interest hospital and physician trade organizations that would be directly impacted by these changes, such as the American Medical Association and the American Hospital Association. Medicare-participating physicians have dealt with significant reimbursement challenges over the past decade under the Sustainable Growth
Rate formula as Congress has repeatedly approved short-term delays in scheduled cuts to providers. This system has created a great deal of uncertainty for providers, and they have consistently advocated for a permanent fix and greater predictability in the Medicare payment system.

Furthermore, the Affordable Care Act includes several other payment and reimbursement reforms that aim to create financial incentives for providers to deliver higher quality of care and achieve better health outcomes, rather than simply providing payment based on the number of services delivered. Some of these other reforms include value-based purchasing, bundled payments, and reduced payments to hospitals with high readmission rates. Many providers and health systems are already taking steps to adapt to these payment and reimbursement changes under the Medicare program. Thus, incorporating comparative effectiveness research into Medicare coverage and reimbursement decisions would be consistent with the general reform movement already being pursued under the Affordable Care Act. Given this trend, and the importance of stability for Medicare providers, it is possible that the hospital lobby and the physician lobby could be moderately supportive of this policy proposal. Engaging providers in the legislative process and ensuring buyin will be critical to gaining this support.

Given the indirect impact that coverage and reimbursement reform would have on Medicare beneficiaries in terms of access to providers and treatments, the senior citizens lobby, including the AARP, is also likely to be involved if this policy change were to be pursued by Congress. Given that the political environment in Congress is growing more receptive to significant Medicare reforms, it is likely in the best interest of current and future beneficiaries to support efforts at payment and delivery reform, rather than cutting program benefits, increasing cost-sharing, or arbitrarily cutting provider payments in a way that threatens access for beneficiaries. 
As with hospital and physician trade organization, engaging beneficiaries through organizations such as the AARP and ensuring adequate buy-in will be critical to gaining support for this policy change.

Finally, in the debate surrounding the passage of the Affordable Care Act in late 2009 and early 2010, there was broad public concern that the use of comparative effectiveness research in coverage and reimbursement decisions would lead to the rationing of health care. Such concerns are likely to resurface if this particular Medicare reform proposal were to be seriously considered before Congress. Though this proposal would provide a broader congressional mandate to the Centers for Medicare and Medicaid Services to utilize comparative effectiveness research in making coverage and reimbursement decisions in the Medicare program, there are several provisions in the original Medicare statute that prevent the use of such information to ration care. These provisions would remain in effect and in some cases are strengthened under the Affordable Care Act, and would also be reinforced in the statutory language of this proposed policy option. A widespread media campaign to disseminate information about these Medicare payment reforms might help to alleviate public concerns, but some pushback would likely still occur. Overall, this proposal is expected to be moderately viable.

\section{Potential Limitations}

Despite the great potential for cost savings in the Medicare program that could result from this policy change, there are also several possible limitations. First, this new process for Medicare coverage and reimbursement decisions could limit access to care for beneficiaries. Some treatment option may no longer be available because providers will be reimbursed at lower rates, and providers may simply stop providing a treatment if the Medicare program no longer covers it. This effect would especially be seen in rural areas and other areas that do not have direct access to an academic medical facility (Pearson and Bach 2010). Additionally, because comparative effectiveness research aggregates data to determine the most effective therapies for a particular condition, it may overlook the fact that some treatment options may be the most effective for a small sub-population of patients (Pearson and Bach 2010). It is not clear how this policy option would address such a situation. Another potential limitation of this policy option is the three-year time frame for generating additional evidence to determine whether a treatment's effectiveness is superior, comparable, or inferior to other related treatment options. While this time frame would likely provide sufficient time for conducting comparative effectiveness research studies, there will also likely be some treatment options that require additional time to thoroughly analyze their effectiveness. However, the three-year probationary period is favored by Drs. Pearson and Bach (2010), the architects of the policy change considered here, because it would create a strong incentive for researchers and the PatientCentered Outcomes Research Institute to conduct expedient research that meets the needs of decision makers within the Centers for Medicare and Medicaid Services.

The terms used for defining superior and comparable treatments also present another potential limitation of this policy change. These definitions are somewhat vague, but similar to the current challenge faced by Centers for Medicare and Medicaid Services in interpreting the meaning of "reasonable and necessary" in making current coverage determinations. Ensuring that these decisions reflect individual patient preferences and responses to various treatment options will likely require ongoing adjustments to how the definitions are interpreted (Pearson and Bach 2010).

Finally, there is also the potential that the most costly treatment options are found to be the most effective, which would contradict the primary purpose of this policy change to reduce costs in the 
Medicare program. Though this may be the case for certain medical conditions or therapies, there are thousands of services covered by Medicare and thus it is likely that there are significant cost savings to be achieved in the program, even if some costly treatments are found to be the most effective. Overall, the potential limitations associated with this policy change are expected to be minimal to moderate.

\section{Option Two: Expand the Use of Accountable Care Organizations in the Medicare Program}

The following section provides a description of the second policy option and then evaluates the proposal based on each of the four criteria described above.

\section{Description of Option Two}

Another policy option to address rising costs in the Medicare program is to transform the way that health care services are delivered to Medicare beneficiaries by requiring the expanded use of Accountable Care Organizations. Research has suggested that integrated care delivery models, such as Accountable Care Organizations, can help reduce the cost of providing health care services while also improving the quality of care delivered (Newman 2011). Thus, the Affordable Care Act required the establishment of a voluntary Accountable Care Organization demonstration program in Medicare by January 2012, called the Shared Savings Program (DHHS 2011c; Newman 2011). Under this program, Accountable Care Organizations are voluntary networks of health care providers, including physicians, hospitals, and other providers such as home health workers and medical product suppliers. This network shares responsibility for providing care to a defined population of patients by coordinating treatment across various care settings, such as the doctor's office, hospitals, and home health care (Gold 2011; DHHS 2011c; Berwick 2011).

The Shared Savings Program requires all participating providers to take joint responsibility for the health of a defined population of patients, a minimum of 5,000 Medicare beneficiaries per Accountable Care Organization, over the course of at least three years. If Accountable Care Organizations are successful in reducing costs and improving the quality of care provided to beneficiaries, beyond what would have otherwise been expected, they are eligible to receive shared savings bonuses from Medicare (Newman 2011). This structure creates incentives for providers to better coordinate care for patients in order to improve health and lower costs; for example, by avoiding unnecessary or duplicative tests and procedures and keeping chronic diseases well-managed (Gold 2011; DHHS 2011c). Under the Shared Savings Program, providers would still receive standard fee-for-service payments based on the number of services provided to Medicare beneficiaries, but providers would also receive shared savings bonus payments for meeting certain cost and quality standards (Berwick 2011; Newman 2011).

Given that payment is based on reduced cost and improved quality of care, there is a certain amount of risk associated with establishing and operating an Accountable Care Organization. If an organization fails to save money or meet quality standards, it would be responsible for the initial costs associated with establishing an Accountable Care Organization, and it may also be required to pay a penalty to the Medicare program for not achieving the intended outcomes of reducing costs and improving quality. The size of this penalty is the subject of future rulemaking. The way this provision of the law was written also gives regulators at the Centers for Medicare and Medicaid Services the discretion to devise other payment methods that could require Accountable Care Organizations to bear even more risk, such as receiving a flat fee per patient for which it assumes care, according to the Medicare Payment Advisory Commission (as cited in Newman 2011), 
similar to the way that capitation payments are made in health maintenance organizations, instead of maintaining the fee-for-service payment structure.

The Shared Savings Program is designed to be different from previous managed care delivery models, such as health maintenance organizations, in order to avoid certain features of these previous models that provoked backlash from both providers and the public. First, insurers or payers do not intervene in the patient-provider relationship in an effort to control costs in Accountable Care Organizations. Instead, the responsibility for being cost-conscious rests with providers, as research has found that the clinical decisions made by physicians account for nearly 87 percent of all personal health spending, whether directly or indirectly, according to Burns and Muller (Newman 2011). Thus, physicians are in a prime position to aid in the reduction of health spending at the patient level. Furthermore, the Shared Savings Program maintains an open panel of providers, meaning the Medicare beneficiaries can still seek care from the physician of their choice, even if that physician operates outside of the beneficiaries' assigned Accountable Care Organization network (DHHS 2011c).

If the Shared Savings Program is successful in achieving at least the minimum projected savings for Medicare by the end of the first three years of operation, the policy option described in this section would mandate the expanded use of Accountable Care Organizations for a broader segment of Medicare beneficiaries in order to realize even more significant savings for the program. The Congressional Budget Office estimates that within the first two years of implementing an Accountable Care Organization-type program within Medicare, nearly 20 percent of traditional fee-for-service beneficiaries will be assigned to physicians participating in an Accountable Care Organization, and participation is expected to grow to 40 percent of the this population by 2019 (New- man 2011). Instead, the goal of this second policy option would be to double participation to at least 80 percent of traditional fee-for-service beneficiaries by 2019 .

\section{Expected Outcomes of Option Two}

\section{Efficacy}

According to estimates from the Centers for Medicare and Medicaid Services, the Medicare Shared Savings Program could save the federal government up to $\$ 960$ million in the first three years of operation (Newman 2011). The Congressional Budget Office has also estimated that the Shared Savings Program could reduce Medicare expenditures by $\$ 4.9$ billion between 2013 and 2019 (Newman 2011). These estimates are based on the assumption that participation would reach 40 percent of the traditional feefor-service Medicare population by 2019. If participation were doubled to 80 percent, the estimated savings could also potentially increase, ranging from nearly $\$ 8$ billion to $\$ 10$ billion in savings over the same time frame, or about $\$ 1.1$ billion to $\$ 1.4$ billion in savings per year. There is also a strong likelihood that more widespread use of Accountable Care Organizations in the Medicare program would improve the quality of care and health outcomes for participating beneficiaries. As explained above, financial incentives for providers under an Accountable Care Organization are directly linked to satisfying certain quality targets determined by the Centers for Medicare and Medicaid Services (Newman 2011). Therefore, providers would also be motivated to improve the quality of care provided to their patients because, if they fail to do so, they would not share in any savings they create for the Medicare program.

\section{Implementation Cost}

The administrative capacity for implementing the Shared Savings Program under the Affordable Care Act already exists within the Center for Medicare 
and Medicaid Innovation, a sub-agency of the Centers for Medicare and Medicaid Services that was also created as part of the Affordable Care Act. This policy option would likely require additional budgetary resources in order to expand the scope of the Shared Savings Program. Given that the Center for Medicare and Medicaid Innovation is already in place, any additional costs are likely to only be minimal and no more than the Medicare program's annual administrative expenses of about $\$ 7$ billion. However, potential costs of implementing the policy change should be considered against expected program savings, as costs should not be greater than potential savings.

\section{Political Feasibility}

Accountable Care Organizations have already gained congressional approval as a Medicare demonstration program under the Affordable Care Act. However, since its passage, the health reform law has been a point of disagreement between the two political parties (Crosson 2011) and it continues to face strong opposition from Republican Members of Congress, including efforts to dismantle the entire law or individual provisions. Nevertheless, the Shared Savings Program has not been a target of these repeal efforts. Despite this broad opposition to the Affordable Care Act, if the Shared Savings Program proves to be successful in reducing costs and improving quality after the first several years of operation, Congress could strongly consider mandating the expanded use of Accountable Care Organizations in Medicare. This move would be even more likely if Congress continues to be receptive to further changes to Medicare that ensure the program's long-term financial stability.

There are several key interest groups that would likely have concerns about a mandated expansion of the Medicare Shared Savings Program. First, physician organizations have expressed concern that hospitals will dominate the creation of new Accountable Care Organizations given their more ready access to capital. In turn, physicians expect Accountable Care Organizations to employ them and closely monitor their relationship with patients. While these concerns have some merit, past experience with integrated care systems have demonstrated the essential role of physician leadership and it would be detrimental to the functionality of the Accountable Care Organization if this leadership was not utilized (Crosson 2011).

Hospitals also have concerns that improved care management under Accountable Care Organizations could lead to vacant hospital beds and thus declining hospital revenues (Crosson 2011), a potential outcome if the current Medicare fee-for-service payment structure were to remain in place and hospitals continued to be reimbursed on a per discharge basis. However, there are several other Medicare initiatives under the Affordable Care Act, such as value-based purchasing and bundled payments, which will begin to move away from the fee-for-service structure and instead pay for quality and outcomes as opposed to the volume of services provided. Between physician and hospital concerns, Accountable Care Organizations present a prime opportunity for all providers to rethink their working relationships and promote a culture of mutual cooperation. Furthermore, the regulations for the Medicare Shared Savings Program promote a strong partnership between hospitals and physicians through governance requirements for the Accountable Care Organizations (Crosson 2011). Finally, public receptivity to Accountable Care Organizations will be crucial to expanding the Shared Savings Program, especially among Medicare beneficiaries. The general public reacted negatively to managed care in the 1990 s (Crosson 2011), rejecting limits on patient choice in selecting providers and capitation payments that often limited the care providers were willing to offer (Mathews 2012). Given this skepticism, public receptivity will likely be dependent on the 
outcomes of early experiences with Accountable Care Organizations, and whether or not they are successful in improving the quality of patient care while reducing overall costs. The key challenge will be to clearly educate the public about Accountable Care Organizations and gain support for expansion of the program. Previous managed care models failed due to lack of support and buy-in from relevant stakeholders, including patients, physicians, hospitals, and insurers (Crosson 2011). If all stakeholders can be made to understand that the success of Accountable Care Organizations is in their common interest, the political feasibility of this policy change is expected to be low to moderately viable.

\section{Potential Limitations}

Despite the potential for reduced costs and improved quality of care, many experts in the field have identified several possible limitations of the Accountable Care Organization delivery model. One such shortcoming is the limited experience with these care delivery models in the US health care system. Only a small number of integrated health care providers exist, such as the Geisinger Health System or Kaiser Permanente, and the start-up phase can be a slow process as organizations must generate operating capital in the range of $\$ 10$ million to $\$ 30$ million, according to Scully and Goldsmith (Mathews 2012), in order to cover the costs of contracting with providers and developing integrated health information technology systems (Newman 2011). These existing integrated systems were purely voluntary creations and it is unclear if mandating this sort of change in the health care system could accomplish similar results in reducing costs and improving the quality of care. Furthermore, quality improvements do not always translate into reduced costs (Newman 2011) and can sometimes lead to even higher costs, as is often the case with new technology or equipment used in the delivery of care (Santerre and Neun 2010).

Another possible shortcoming of this policy option is that as networks of providers become more integrated, these organizations have the potential to consolidate local market power in negotiating prices with other private payers. This increased market power could potentially lead to higher rates for health care services, even if care is ultimately being provided in a more efficient manner, according to Berenson, Ginsburg, and Kemps (Newman 2011). This outcome would effectively increase costs in the US health care system as a whole, even if the intended effect of slowing cost growth in the Medicare program is realized. Finally, the Medicare Shared Savings Program only addresses hospital and physician services provided under Parts $\mathrm{A}$ and $\mathrm{B}$ of the program, but not the prescription drug benefit provided under Part D (Newman 2011). Medicare Part D is projected to grow annually at a faster rate than Part B (Medicare Board of Trustees 2011), yet this policy option does not address costs in this portion of the program. Thus, any savings realized in Parts A and B through this second policy option could potentially be negated by uncontrolled cost growth in Part D. Overall, the potential limitations associated with this policy change are expected to be minimal to moderate.

\section{Option Three: Chairman Ryan's Premium Support Model for Medicare}

The following section provides a description of the third policy option and then evaluates the proposal based on each of the four criteria described in the introduction.

Description of Option Three

A final policy option is to fundamentally restructure the Medicare program by transforming it into a premium support model, based on the proposal put forward by House Budget Committee Chairman Paul Ryan (R-WI) in his FY 2012 Budget Resolution, which passed the House of Representatives in April 2011 (Fuchs and Potetz 2011). Under the exist- 
ing Medicare program, beneficiaries are guaranteed a defined set of benefits, meaning that the federal government covers the cost of all benefits that are promised to beneficiaries under law (Fuchs and Potetz 2011). However, under the Ryan premium support model, beneficiaries would receive a defined amount of money from the federal government in order to purchase a private health insurance plan (Fuchs and Potetz 2011; Van de Water 2011). Under this plan, beginning in 2022, newly-eligible Medicare beneficiaries would receive a premium support subsidy in order to purchase a private health insurance plan with a benefits package containing certain minimum coverage requirements, and the subsidy would be paid directly to the health plan from Medicare (US House of Representatives 2011). The size of premium support payments for each beneficiary would vary based on the beneficiary's income and health status, and the beneficiary would be required to pay the difference for a health insurance plan that exceeds the amount of the government's contribution (Fuchs and Potetz 2011). The base subsidy amount for the typical 65yearold in 2022 would be $\$ 8,000$, which would be approximately the same amount as the projected federal spending per beneficiary in the traditional fee-for-service Medicare program that same year (CBO 2011).

Based on beneficiary income, those who are wealthier would receive a smaller subsidy than lower-income beneficiaries (US House of Representatives 2011). Specifically, the top two percent of beneficiaries, based on the annual income distribution, would receive a subsidy that equals 30 percent of the base premium support amount. The next six percent of beneficiaries, based on the annual income distribution, would receive a subsidy equal to 50 percent of the base premium support amount, and the remaining 92 percent of beneficiaries would receive the full base premium support amount (CBO 2011). The size of the premium support subsidy would also vary based on the health status of the beneficiary (CBO 2011; Van de Water 2011) such that those in poorer health would receive a larger subsidy relative to those in better health. The premium support subsidy would increase over time based on annual increases in overall consumer prices (as tracked by the Consumer Price Index for All Urban Consumers, or CPI-U) and with the age of the beneficiary (CBO 2011), as older beneficiaries are likely to be in poorer health and have higher health care costs.

In addition to a larger premium support subsidy, low-income beneficiaries would also receive financial assistance from the Medicare program in order to cover their out-of-pocket health care costs (US House of Representatives 2011), as opposed to receiving cost-sharing assistance through the Medicaid program, as low-income individuals eligible for both Medicare and Medicaid currently do (Van de Water 2011). Instead, the government would deposit additional funds into a Medical Savings Account that low-income beneficiaries would then use to cover costsharing and other out-of-pocket costs in their health plan, such as deductibles and coinsurance (Fuchs and Potetz 2011). Like the overall premium support subsidy, the amount deposited into Medical Savings Accounts would grow each year indexed to the CPI-U. Under the Ryan plan, the government's contribution to each Medical Savings Account in 2022 would be approximately $\$ 7,800$ for beneficiaries with incomes below 100 percent of the Federal Poverty Level (Fuchs and Potetz 2011).

In order to implement the Ryan proposal, a tightly-regulated Medicare exchange would be established in which private insurers would compete to cover program beneficiaries. This proposal would require participating health plans to offer coverage to all Medicare beneficiaries in order to prevent insurers from engaging in risk selection where they seek out the healthiest and least-costly beneficiaries for coverage (US House of Representatives 2011). Private insurers offering 
plans in the Medicare exchange would be required to charge the same premiums for all beneficiaries of the same age (CBO 2011). The Ryan proposal would also create a risk adjustment mechanism within the Medicare exchange such that the program would gather fees from private plans sold in the exchange that have healthier and thus less-costly enrollees. Those collected funds would then be distributed to plans that have sicker and therefore more-costly enrollees. This risk adjustment mechanism is intended to compensate health plans in the Medicare exchange for the health risks associated with their particular insured population (CBO 2011).

Finally, the Ryan proposal would maintain the traditional fee-for-service Medicare program for current beneficiaries and for those individuals who become eligible for the program before the transition to a premium support model in 2022. Beyond that, existing Medicare beneficiaries would have the option to transition from traditional Medicare into the premium support system (US House of Representatives 2011), but newly-eligible enrollees would not have the option of moving from premium support back to the traditional Medicare program.

\section{Expected Outcome of Option Three}

\section{Efficacy}

Based on its design, the premium support model proposed by Chairman Ryan is expected to reduce federal expenditures on Medicare, making the government's contribution to the program more predictable and manageable over time (Fuchs and Potetz 2011). Medicare costs would become more predictable because the government's per capita contribution to the program would be known in advance. Furthermore, the amount of the subsidy could be adjusted in order to meet specific budgetary goals, especially if the government's contribution is not linked to the underlying cost of plan premiums, as in the case under the
Ryan proposal (Fuchs and Potetz 2011). According to the Congressional Budget Office's preliminary analysis of the Ryan plan, it is estimated that significant federal savings will be achieved under this proposal in the long run, even if the overall health care costs continue to rise (CBO, 2011; Fuchs and Potetz 2011). If the Medicare program continued to exist in 2022 in its current form, it is estimated that the federal government would cover, on average, approximately 60 percent of total health spending per beneficiary. However, under the Ryan proposal, it is estimated that the federal government would only cover about 40 percent of total health spending per beneficiary, on average (Greenstein 2011). Based on this expected reduction in the government's contribution to Medicare spending under the Ryan proposal, and also based on projected program expenditures in 2022 from the Congressional Budget Office (2012), it is estimated that this policy change could save the federal government approximately \$200 billion annually in the Medicare program.

The nature of the premium support model envisioned in the Ryan proposal also suggests that the quality of care provided to beneficiaries and their health outcomes could potentially be worsened, or at best, not impacted at all by the policy change. At the present time, the traditional Medicare program is undergoing several payment and delivery reforms under the Affordable Care Act that reward providers for higher quality care and better health outcomes, such as Hospital Value-Based Purchasing and financial penalties for certain types of hospital readmissions (DHHS 2011d). However, under the Ryan proposal, newly-eligible beneficiaries and some existing beneficiaries will receive their health coverage through private plans, most of which will continue to operate under a feefor-service payment structure, compensating physicians based on the quantity of services provided. While fee-for-service does not always translate into poor quality care and health outcomes, this incentive struc- 
ture has proven problematic and motivated the transition to systems that reward quality and improved health outcomes. Furthermore, the Ryan proposal guarantees a defined subsidy amount for newly-eligible Medicare beneficiaries to aid in the purchase of private health coverage. Thus, low-income beneficiaries who do not have the financial means to pay premiums beyond the subsidy amount may have to settle for a cheaper health plan offered in the Medicare exchange. A cheaper plan would likely offer less comprehensive benefits or have a smaller provider network, both of which might jeopardize the beneficiaries' quality of and access to care (Van de Water 2011), potentially leading to poorer health outcomes.

\section{Implementation Cost}

At the present time, there are no official cost estimates for implementing this policy change. However, examining the current administrative structure for the Medicare program and expected changes under the policy proposal suggests that implementation costs to the federal government would likely increase. The Centers for Medicare and Medicaid Services, the administrative agency for Medicare, already exists to administer the program in its current form. However, it is likely that additional appropriations would be necessary in order to transition the program to the premium support model, with the federal government responsible for determining subsidies and managing risk management for the new program. Furthermore, the traditional Medicare program would be maintained for existing beneficiaries, even as newly-eligible beneficiaries participate in the premium support program. Thus, the Centers for Medicare and Medicaid Services would essentially be responsible for administering two versions of the Medicare program, possibly for a few decades, until there are no longer any beneficiaries participating under the traditional program. It is also expected that as the size of the traditional Medicare population shrinks, the cost of administering the traditional program would likely increase relative to payments for benefits (Van de Water 2011). Given that administrative expenses for the Medicare program were $\$ 7$ billion in 2010 (Medicare Board of Trustees 2011), a conservative cost estimate would see the costs of administering the Medicare program increase by 50 percent to 100 percent, or $\$ 3.5$ billion to $\$ 7$ billion under this policy change.

\section{Political Feasibility}

If enacted, this policy proposal would significantly change the nature of the entitlement under the Medicare program (CBO 2011; Fuchs and Potetz 2011), the most sweeping change to the Medicare program since its enactment in 1965. Following the release of Chairman Ryan's Medicare premium support plan in April 2011 as part of the House Republican FY 2012 Budget Resolution, Democratic members of Congress reacted strongly against the proposal. Democratic Minority Leader Nancy Pelosi (D-CA) stated that the plan would effectively end guaranteed health benefits for beneficiaries under the Medicare program (as cited in Montgomery and Rucker 2011). Since the Ryan proposal was put forward, only one Democrat, Senator Ron Wyden (D-OR), has come forward and expressed support for utilizing a premium support model in the Medicare program. Although, Senator Wyden prefers to maintain traditional Medicare as an option for beneficiaries, a structure that Chairman Ryan utilized in his more recent FY 2013 Budget Resolution released in March 2012.

Despite this small bipartisan display, Democrats in Congress have continued to express strong opposition to making significant structural changes to the Medicare program, especially heading into the 2012 election. This lack of consensus on the premium support model makes it almost certain that the proposal will not be acted on in the second session of the $112^{\text {th }}$ Congress, but may face fur- 
ther consideration depending on the outcomes of the November 2012 elections.

Beyond Congress, there has been similar public outcry in response to Chairman Ryan's proposal, especially among senior citizens and groups like the AARP. Although Ryan's proposal would not change Medicare coverage for current beneficiaries and those who are currently 55 or older, many seniors have expressed concerns over the significantly increased cost-sharing requirements they would face under a premium support model. Furthermore, seniors have expressed concern that any Medicare premium support model considered by Congress may not maintain the age cutoff for remaining in traditional Medicare, rather shifting all beneficiaries into the new program (Barry 2011). Polling conducted shortly after the release of the Ryan plan found that senior citizens prefer to keep the Medicare program in its current form by a two-to-one margin (KFF 2011). Additional polling conducted in April 2011 suggests that the general public is not very familiar with the premium support concept for the Medicare program. Fifty-eight percent of those polled had never heard of the term "premium support" while another 28 percent had heard of the term, but were uncertain what it meant (KFF 2011). More generally, the public is nearly evenly split on whether or not to maintain the Medicare program in its existing form, with 50 percent of those polled preferring to keep the program as is and 46 percent favoring some sort of the change in the program. However, these opinions appear rather malleable. When those preferring to keep the current Medicare program were questioned further about making changes to reduce the federal deficit and protect the program for future generations, 54 percent then said they would be open to changing Medicare. Alternatively, those who initially favored changes to the program were told more details about changes to Medicare, including ending the program in its current form and enrolling beneficiaries in private plans, 68 per- cent of those polled then said they would prefer to keep Medicare as is (KFF 2011).

This polling suggests several things. First, the public does not appear to have a deep understanding of the nature of the premium support model for Medicare that is being considered, and the implications of that policy change for existing and future beneficiaries. Second, public opinion in the poll was fluid when provided with additional details about potential changes to the Medicare program, and public opinion especially hardened against making changes when those polled learned more about the nature of the proposed changes. These shifts in opinion make it difficult to gauge whether or not the public would be supportive of such a significant change to traditional Medicare. Considering the opposition from congressional Democrats, the opposition of senior citizens to fundamental changes to the Medicare program, and volatility of public opinion on the issue, the political feasibility of this proposal is expected to be low.

\section{Potential Limitations}

One potential limitation of the Ryan proposal relates to how premium support payments increase over time. Under this proposal, the size of the subsidy is linked to general inflation for urban consumers, or the CPI-U. However, based on both historical inflation trends and generally-accepted future projections, this method for indexing the annual subsidy growth will not keep pace with the rising cost of health care in the US. From 1985 to 2009, the average annual growth in Medicare spending per capita was approximately 7 percent and average annual growth in overall national health spending per capita was about 6.3 percent (Fuchs and Potetz 2011). These average annual growth rates significantly outpaced the CPI-U in the same time frame, which grew at an average annual rate of 2.9 percent, according to The Economic Report of the President from 2011 (Fuchs and Potetz 2011). While it is clear that the Ryan 
proposal would greatly reduce federal spending in the Medicare program, the Congressional Budget Office found, in conducting its preliminary analysis of the plan, that these federal savings would only be achieved by increasing the costsharing burden for beneficiaries, not by reducing the overall cost of providing coverage through Medicare (Fuchs and Potetz 2011). According to the Congressional Budget Office, the typical 65 year-old Medicare beneficiary in 2022 would pay more than twice as much under the Ryan premium support plan than under traditional Medicare. In this year, the federal government contribution for the typical 65 year-old beneficiary is expected to be $\$ 8,000$, and the beneficiary would then be responsible for approximately $\$ 12,500$ in annual out-of-pocket health care costs, on average, compared to $\$ 5,630$ in expected out-of-pocket costs per beneficiary under the traditional Medicare program in that same year, according to estimates from the Kaiser Family Foundation (Fuchs and Potetz 2011). These increased costs for beneficiaries reflect the fact that government subsidies would not keep pace with growth in the cost of health care services, forcing beneficiaries to either pay more out of pocket in order to purchase coverage or settle for a less expensive plan that may provide less comprehensive coverage or may be of lower quality (Van de Water 2011).

Another potential limitation of the Ryan proposal relates to transitioning to the premium support model and phasing out traditional Medicare. Beginning in 2022, newly-eligible beneficiaries would be enrolled in premium support with no new beneficiaries enrolling in the traditional Medicare program. Over time, the traditional Medicare population will become older, sicker, and fewer in number. As a result, it will become increasingly expensive to provide health coverage to this group of beneficiaries that remain in traditional Medicare. Furthermore, private plans could accelerate this trend by attracting healthier traditional Medicare benefi- ciaries to premium support, as is permitted under the Ryan plan. As the number of beneficiaries participating in traditional fee-for-service Medicare decreases over time, the cost of administering traditional Medicare will thus increase relative to the cost of benefits being paid out. Traditional Medicare generally has a high degree of market power to negotiate lower payment rates with providers, due to its large population of beneficiaries. However, this power would be weakened with a decrease in the number of traditional Medicare beneficiaries, leaving providers with little incentive to continue participating in the traditional program. Therefore, it would be difficult to keep traditional Medicare operational alongside the premium support system without increasing provider reimbursement rates and beneficiary premiums in the traditional system. This outcome will likely have a significant negative impact on traditional Medicare beneficiaries beyond 2022, negating the claim that the Ryan proposal would have no impact on those beneficiaries currently enrolled in traditional Medicare (Van de Water 2011).

Finally, changes to Medicare under the Ryan proposal would also severely undermine the program's prominent role in the US health care system. Medicare is the largest purchaser and regulator of health care in the US and it exerts significant influence on private insurers and other public systems (Van de Water 2011). Given this market power, Medicare has often led the way on innovative coverage, reimbursement, and delivery policies that aim to control health care spending. If traditional Medicare were to ultimately be eliminated under the Ryan proposal, the government would also lose the opportunity to use the program to promote cost reduction throughout the entire US health care system because diffusing expenditures across a large number of private plans would diminish Medicare's market power and leverage in negotiating reimbursement rates with providers, according to work from Dowd et al., 
Mayes and Berenson, and Vladeck, Van de Water, and Eichner (Van de Water 2011). The policy change would also put in jeopardy significant Medicare reforms under the Affordable Care Act that aim to control costs by fundamentally changing the way that health care is delivered and paid for in the US. Overall, the potential limitations associated with this policy change are expected to be significant.

\section{Policy Recommendations and Conclusion}

\section{Recommendations}

Table 1 presents a decision matrix with the projected outcomes for each of the three policy options as evaluated on the four criteria. Based on these projections, and considering tradeoffs between each criterion, the most successful policy option to address rising costs in the Medicare program is the first option: incorpo- rating comparative effectiveness research into Medicare coverage and reimbursement decisions. This policy option is expected to achieve the most significant savings for Medicare at $\$ 131$ billion to $\$ 262$ billion in savings annually, which would have a significant impact on bending the cost curve for the program. Additionally, this first policy option would likely improving the quality of care and health outcomes for beneficiaries. Furthermore, implementing the policy change is expected to impose only minimal costs on the federal government at less than $\$ 7$ billion annually, and the political feasibility of the policy option is expected to be moderately viable. Finally, the potential limitations associated with the policy change are only expected to be minimal to moderate, and would not greatly alter expected outcomes on the first three criteria. Given Medicare's significant financial challenges, reducing program

Table 1: Projected Outcomes.

\begin{tabular}{|c|c|c|c|c|c|}
\hline Policy Options & $\begin{array}{l}\text { Reducing } \\
\text { Medicare } \\
\text { Spending }\end{array}$ & $\begin{array}{l}\text { Quality } \\
\text { and Health } \\
\text { Outcomes }\end{array}$ & $\begin{array}{l}\text { Implemen- } \\
\text { tation Cost }\end{array}$ & $\begin{array}{l}\text { Political } \\
\text { Feasibility }\end{array}$ & $\begin{array}{l}\text { Potential } \\
\text { Limitations }\end{array}$ \\
\hline $\begin{array}{l}\text { One: Incorpo- } \\
\text { rate Compara- } \\
\text { tive Effective- } \\
\text { ness Research } \\
\text { into Medicare } \\
\text { Coverage and } \\
\text { Reimbursement } \\
\text { Decisions }\end{array}$ & $\begin{array}{l}\text { Approximately } \\
\$ 131 \text { billion to } \$ 262 \\
\text { billion annually } \\
\text { (Significant) }\end{array}$ & $\begin{array}{l}\text { Likely to } \\
\text { improve }\end{array}$ & $\begin{array}{l}\text { Minimal, } \\
\text { likely less } \\
\text { than } \$ 7 \\
\text { billion an- } \\
\text { nually }\end{array}$ & $\begin{array}{l}\text { Moderate } \\
\text { viability }\end{array}$ & $\begin{array}{l}\text { Minimal to } \\
\text { moderate }\end{array}$ \\
\hline $\begin{array}{l}\text { Two: Expanded } \\
\text { Use of Ac- } \\
\text { countable Care } \\
\text { Organizations } \\
\text { in Medicare }\end{array}$ & $\begin{array}{l}\text { Approximately } \\
\$ 1.1 \text { billion to } \$ 1.4 \\
\text { billion annually } \\
\text { (Insignificant) }\end{array}$ & $\begin{array}{l}\text { Likely to } \\
\text { improve }\end{array}$ & $\begin{array}{l}\text { Minimal, } \\
\text { likely less } \\
\text { than } \$ 7 \\
\text { billion an- } \\
\text { nually }\end{array}$ & $\begin{array}{l}\text { Low to } \\
\text { moderate } \\
\text { viability }\end{array}$ & $\begin{array}{l}\text { Minimal to } \\
\text { moderate }\end{array}$ \\
\hline $\begin{array}{l}\text { Three: Chair- } \\
\text { man Ryan's } \\
\text { Premium Sup- } \\
\text { port Model for } \\
\text { Medicare }\end{array}$ & $\begin{array}{l}\text { Approximately } \\
\$ 200 \text { billion annu- } \\
\text { ally (Significant) }\end{array}$ & $\begin{array}{l}\text { Likely to } \\
\text { worsen or } \\
\text { have no } \\
\text { impact }\end{array}$ & $\begin{array}{l}\text { Minimal, } \\
\text { likely } \$ 3 \cdot 5 \\
\text { billion to } \\
\$ 7 \text { billion } \\
\text { annually }\end{array}$ & $\begin{array}{l}\text { Low } \\
\text { viability }\end{array}$ & Significant \\
\hline
\end{tabular}


expenditures is an imperative objective of any policy change that is pursued. While the third policy option is also expected to achieve significant savings for the Medicare program at approximately $\$ 200$ billion annually, this policy change would likely have a negative impact on the quality of care and health outcomes for beneficiaries. Furthermore, there are significant limitations associated with this policy change that would significantly impact outcomes on the other criteria, especially as the monetary savings created for the federal government would be shifted onto Medicare beneficiaries in the form of higher cost-sharing. While this third policy option would greatly reduce the federal government's financial commitment to Medicare, it also does not directly address factors that underlie the cost of providing health care, such as the mechanisms for making coverage and reimbursement decisions, the organization and delivery of health care services, and the financial incentives that are in place for providers. Though the third policy option is expected to create significant Medicare savings and more predictable future expenditures in the program, Congress should not be short-sighted in pursuing this policy change without giving full consideration to the adverse impact that this reform would likely have on the beneficiaries that the program is intended to serve. Based on the analysis presented here, it is not recommended to pursue the third policy option in its existing form.

\section{Conclusion}

Many budget experts and health policy analysts have acknowledged that the long-term fiscal outlook for the Medicare program will be difficult to sustain in its current form. While the Affordable Care Act included many reforms that ensure the short-term solvency of the program, changing demographics in the US population and the rising cost of providing health care will continue to strain Medicare if no further changes are made to the program. Given these challenges, it is in the best financial interest of Congress to pursue additional reforms to ensure the financial viability of the program.

Based on the analysis presented in this paper, the first policy option, which would incorporate the findings of comparative effectiveness research into Medicare coverage and reimbursement decisions, would be the most successful in achieving Congress's primary goals of reducing Medicare expenditures and improving quality of care and health outcomes for beneficiaries. Furthermore, the first policy option would achieve these objectives without significant limitations or unintended consequences. However, the analysis presented here should not be interpreted to suggest that Medicare coverage and reimbursement reform is the only possible approach to achieving these desired outcomes. All viable policy options that are likely to achieve significant savings with few unintended consequences should be strongly considered by Congress and will be imperative to address present and future financial strains on the Medicare program.

While consensus on the best path forward for Medicare has been difficult to reach, recent developments hold promise. In the past 15 months, both political parties have begun to recognize the dire problems that face the Medicare program and have demonstrated a willingness to at least come to the table for further discussion. However, the often political nature of the current conversation about Medicare spending, and health care spending in the US more generally, demonstrates just how difficult it is to have an open and thoughtful discussion about this pressing issue. In order to move forward with an honest conversation, members of both parties must acknowledge the inherent resource constraints that exist in the US economy, and also recognize that reigning in health care spending in the US, especially in a large public program like Medicare, will require some difficult tradeoffs between competing interests. The time is now for elected officials to make difficult but responsible 
choices, develop creative policy solutions in order to accomplish more with less (Neumann 2012), and preserve the prom- ise of the Medicare program for current and future generations of beneficiaries.

\section{References}

Barry, Patricia. 2011. "Medicare in the Crosshairs: Budget talks' focus on Medicare makes older Americans nervous." AARP Bulletin. May 5. Accessed February 3, 2012. http://www.aarp.org/health/medicare-insurance/info-05-2011/medi care-in-the-crosshairs.html.

Berwick, Donald M. 2011. "Making Good on ACOs' Promise: The final Rule for the Medicare Shared Savings Program." New England Journal of Medicine 365 (19): 1753-1756.

CBO (Congressional Budget Office). 2011. Long-Term Analysis of a Budget Proposal by Chairman Ryan. Washington, DC: Congressional Budget Office.

---. 2012. "Mandatory outlays projected in CBO's baseline." The Budget and Economic Outlook: Fiscal Years 2012 to 2022. January 21. Accessed February 3. http://cbo.gov/doc.cfm?index=12699.

Copeland, Curtis W. 2010. "New Entities Created Pursuant to the Patient Protection and Affordable Care Act, R41315.” Prepared by the Congressional Research Service, Washington, DC.

CEA (Council of Economic Advisors). 2009. "The Economic Case for Health Care Reform." Executive Office of the President of the United States.

Crosson, Francis J. 2011. "The Accountable Care Organization: Whatever Its Growing Pains, The Concept Is Too Vitally Important To Fail.” Health Affairs 30 (7): 1250-1255.

Davis, Patricia A. 2011. “Medicare Financing, R41436.” Prepared by the Congressional Research Service, Washington, DC.

Davis, Patricia A., Paulette C. Morgan, Cliff Binder, Jim Hahn, David Newman, Mark Newsom, and Sibyl Tilson. 2011. "Medicare Primer, R40425." Prepared by the Congressional Research Service, Washington, DC.

Devers, Kelly, and Robert Berenson. 2009. "Can Accountable Care Organizations Improve the Value of Health Care by Solving the Cost and Quality Quandaries?” The Robert Wood Johnson Foundation and the Urban Institute.

DHHS (Department of Health and Human Services). 2011a. Centers for Medicare and Medicaid Services. "National Health Expenditure Projections 2010-2020." National Health Expenditure Accounts. Accessed January 3, 2012. http:// www.cms.gov/NationalHealthExpendData/downloads/ proj2010.pdf.

- - . 2011b. "Accountable care organizations: Improving care coordination for people with Medicare." Accessed February 3, 2012. http://www.natlawreview.com/ article/accountable-care-organizations-improving-care-coordinationpeoplemedicare.

- - . 2011c. Centers for Medicare and Medicaid Services. "Summary of proposed rule provisions for Accountable Care Organizations under the Medicare Shared Savings Program.” Press Release, March 31.

- - . 2011d. "Administration Implements New Health Reform Provision to Improve Care Quality, Lower Costs." Newsroom: Fact Sheet. April 29, 2011. Accessed February 3, 2012. http://www.healthcare.gov/news/factsheets/2011/04/ valuebasedpurchasingo4292011a.html. 
---. 2012a. Centers for Medicare and Medicaid Services. "National Health Expenditure Web Tables.” National Health Expenditure Accounts. Accessed March 27. https://www.cms.gov/NationalHealthExpendData/downloads/ tables.pdf.

---. 2012b. Centers for Medicare and Medicaid Services. "NHE Fact Sheet." Last modified March 26. Accessed March 27. https://www.cms.gov/ResearchStatistics-Data-and-Systems/Statistics-Trends-and-Reports/National HealthExpendData/NHE_Fact_Sheet.html.

Emanuel, Ezekiel J. (2012). "Where Are the Health Care Cost Savings?” Journal of the American Medical Association 307 (1): 39-40.

Fuchs, Beth, and Lisa Potetz. 2011. "The Nuts and Bolts of Medicare Premium Support Proposals.” Prepared for the Henry J. Kaiser Family Foundation, Menlo Park, CA.

Gold, Jenny. 2011. "ACO is the hottest three-letter word in health care." Kaiser Health News. October 21. Accessed January 20, 2012. http://www.kaiserhealthnews. org/stories/2011/january/13/aco-accountable-care-organization-faq.aspx.

Greenstein, R. 2011. “CBO Report: Ryan Plan Specifies Spending Path That Would Nearly End Most Of Government Other Than Social Security, Healthcare, And Defense By 2050: Plan Also Contains Deeper Cuts To Medicare And Medicaid Than Ryan Revealed.” Prepared by the Center on Budget and Policy Priorities, Washington, DC.

Hahn, Jim, and Janemarie Mulvey. 2011. "Medicare Physician Payment Updates and the Sustainable Growth Rate (SGR) System, R40907.” Prepared by the Congressional Research Service, Washington, DC.

KFF (Kaiser Family Foundation). 2011. "Kaiser Health Tracking Poll: Public Opinion on Health Care Issues.” Prepared by The Henry J. Kaiser Family Foundation, Menlo Park, CA. Accessed February 3, 2012. http://www.kff.org/kaiser polls/8180.cfm.

KaiserEDU.org. 2012. "Costs and Spending.” Topics. The Henry J. Kaiser Family Foundation. http://www.kaiseredu.org/Topics/Costs-and-Spending.aspx

Martin, Anne B., David Lassman, Benjamin Washington, Aaron Catlin, and The National Health Expenditures Accounts Team. 2012. "Growth in US Health Spending Remained Slow In 2010; Health Share Of Gross Domestic Product Was Unchanged From 2009.” Health Affairs 31 (1): 208-219.

Mathews, Anna W. (2012). "Can Accountable-Care Organizations Improve Health Care While Reducing Costs?” January 23. Accessed Feburary 3.

The Wall Street Journal. http://online.wsj.com/article_email/SB 10001424052970204720204577128901714576054-lMyQjAxMTAyMDIw MzEyNDMyWj.html?mod=wsj_share_email.

Medicare Board of Trustees. 2011. 2011 Annual Report of The Boards of Trustees of The Federal Hospital Insurance and Federal Supplementary Medical Insurance Trust Funds. Washington, DC: Boards of Trustees of the Federal Hospital Insurance and Federal Supplementary Medical Insurance Trust Funds.

Montgomery, Lori. 2011. "Medicare spending growth rising slower but enrollment will rise.” The Washington Post. December 22. Accessed January 3, 2012. http://www.washingtonpost.com/business/economy/medicare-spendinggrowth-rising-slower-but-enrollment-will-rise/2011/12/15/gIQATcIMCP_ story.html?wpisrc=emailtoafriend.

Montgomery, Lori, and Phil Rucker. 2011. "House Republicans unveil \$3.5 trillion 
budget blueprint for 2012." The Washington Post. April 5. Accessed January 3, 2012. http://www.washingtonpost.com/business/economy/house-republi cans-unveil-35t-budget-blueprint-for-2012/2011/04/05/AFT6IDjC_story. html.

Neumann, Peter J. (2012). "What We Talk about When We Talk about Health Care Costs." New England Journal of Medicine 366(7): 585-586.

New York Times Editorial Board. (2011). "Fixing Medicare." The New York Times. November 21. Accessed January 3, 2012. http://www.nytimes.com/2011/11/21 /opinion/fixing-medicare.html?emc=eta1.

Newman, David. (2011). "Accountable Care Organizations and the Medicare Shared Savings Program, R41474.” Prepared by the Congressional Research Service, Washington, DC.

OECD (Organization for Economic Co-operation and Development). 2011. “Total Health Expenditures as \% of GDP, 2007-2009." A System of Health Accounts. Accessed January 3, 2012. http://www.oecd.org/document/8/ o,3746,en_2649_34631_2742536_1_1_1_1,oo.html.

Pear, Robert. 2011. "Support Builds for a Plan to Rein in Medicare Costs." The New York Times. November 25. Accessed January 3, 2012. http://www.ny times.com/2011/11/25/us/politics/support-builds-for-premium-support-planfor-medicare.html?scp=1\&sq=support\%2obuilds\%2ofor\%20plan\%20to\%20 rein\%2oin\%2oMedicare\&st=cse.

Pearson, Steven D., and Peter B. Bach. (2010). "How Medicare Could Use Comparative Effectiveness Research In Deciding On New Coverage And Reimbursement." Health Affairs 29 (10): 1796-1804.

Roy, Avik. 2011. “Saving Medicare from Itself.” National Affairs 8 (Summer 2011): 35-55. Accessed March 16, 2012. http://www.nationalaffairs.com/ doclib/20110623_Roy.pdf.

Santerre, Rexford E., and Stephen P. Neun. (2010). Health Economics: Theory, In sight, and Industry Studies, $5^{\text {th }}$ Edition. Mason, OH: South-Western Cengage Learning.

Seiguer, Erica. 2005. "Health Care: What is Reasonable and Necessary?” Web Weekly: News from the Harvard Medical Community. Accessed February 3, 2012. http://webweekly.hms.harvard.edu/ archive/2005/10_31/student_scene. html.

Sisko, Andrea M., Christopher J. Truffer, Sean P. Keehan, John A. Poisal, M. Kent Clemens, and Andrew J. Madison. (2010). "National Health Spending Projections: The Estimated Impact Of Reform Through 2019.” Health Affairs 29 (10): 1933-1941.

US House of Representatives. 2011. House Committee on the Budget. The Path to Prosperity, Restoring America's Promise: Fiscal Year 2012 Budget Resolution. Washington, DC.

Van de Water, Paul N. 2011. "Converting Medicare To Premium Support Would Likely Lead To A Two Tier Health Care System.” Prepared by the Center for Budget and Policy Priorities, Washington, DC. 
Ashley Flint is in her final year of the Master of Public Policy program at The George Washington University where she is concentrating in health policy. She earned a Bachelor of Arts degree at Emory University, majoring in Political Science and Psychology. Prior to moving to Washington, DC for graduate school, Ashley worked in a pediatrics office, an experience that inspired her to pursue a career in health policy. She currently works as an Associate for HCM Strategists and enjoys being active.

The author thanks editors Anne Berry, Rebecca Dilday, Rachel Brody, and Joshua Nadas for their thoughtful comments and support throughout the editing process. The author would also like to thank Dr. Robert Stoker and Dr. Nancy Augustine for their feedback on drafts of the article. Finally, the author would like to thank her family and friends for their encouragement and support over the past several months. 